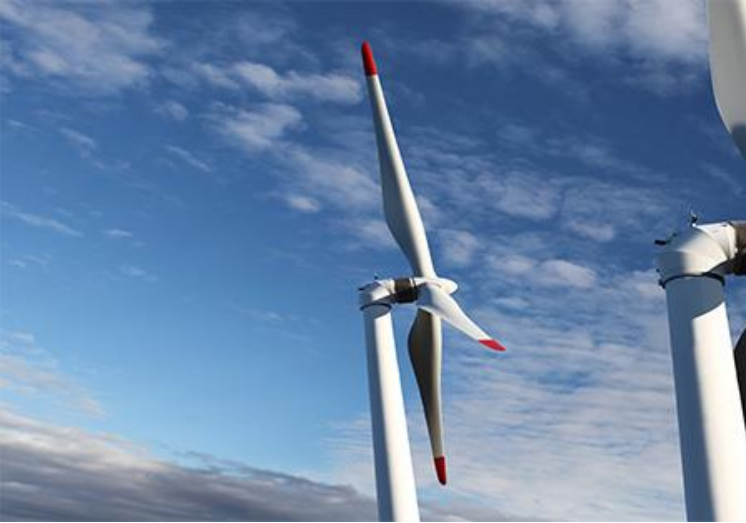

\title{
Friction moments of ball joint supports used in structural test rigs subjected to cyclic loading
}

Malo Rosemeier, Thomas Gebauer, Catherine Lester and Moritz Bätge Presented by David Melcher

$7^{\text {th }}$ International Conference on Structural Engineering, Mechanics and Computation (SEMC) September 2-4, 2019, Cape Town, South Africa. 


\section{Motivation}

1) Understand the structural response of a ball joint supported specimen subjected to bending and torsion

2) Determine friction coefficients and thus friction moment of the joints

3) Validate finite element models

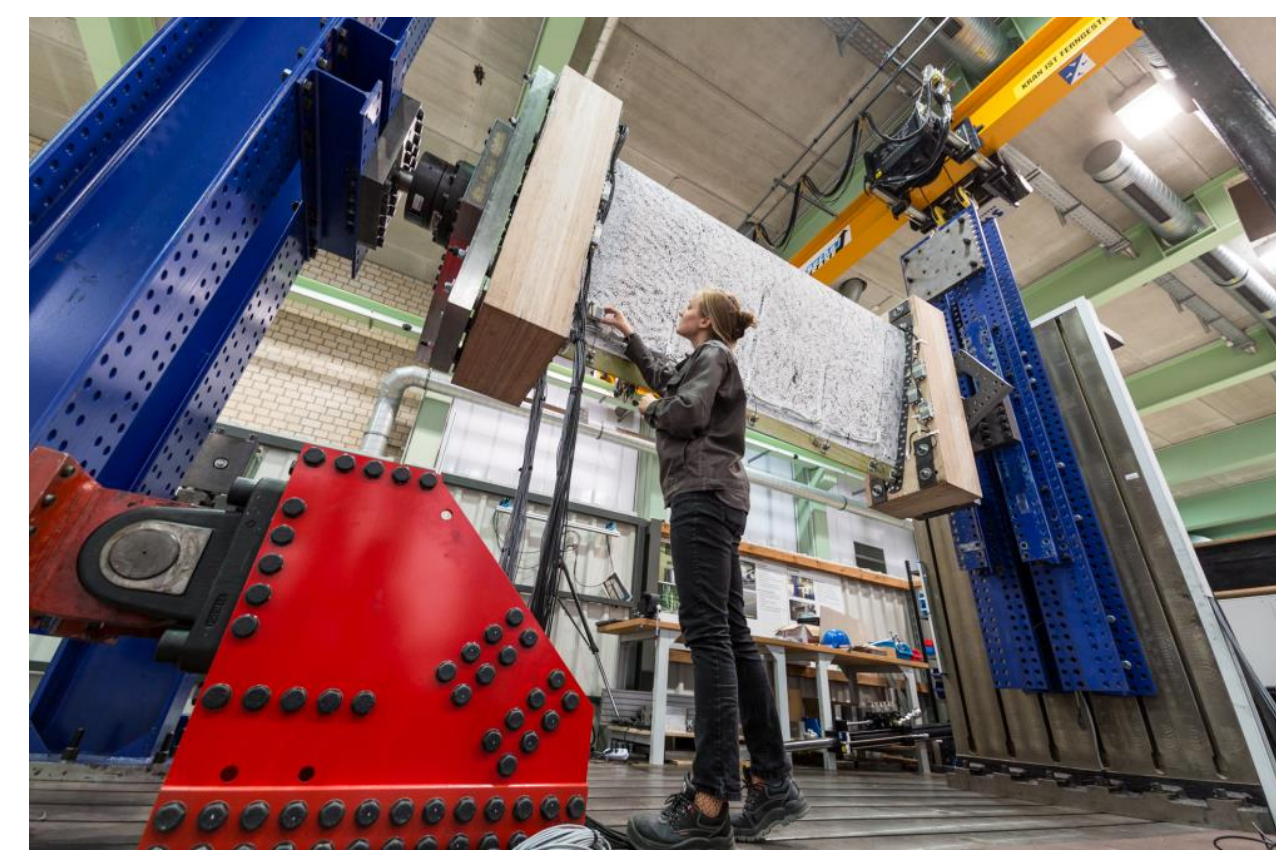




\section{Method}

\section{Ball joint}
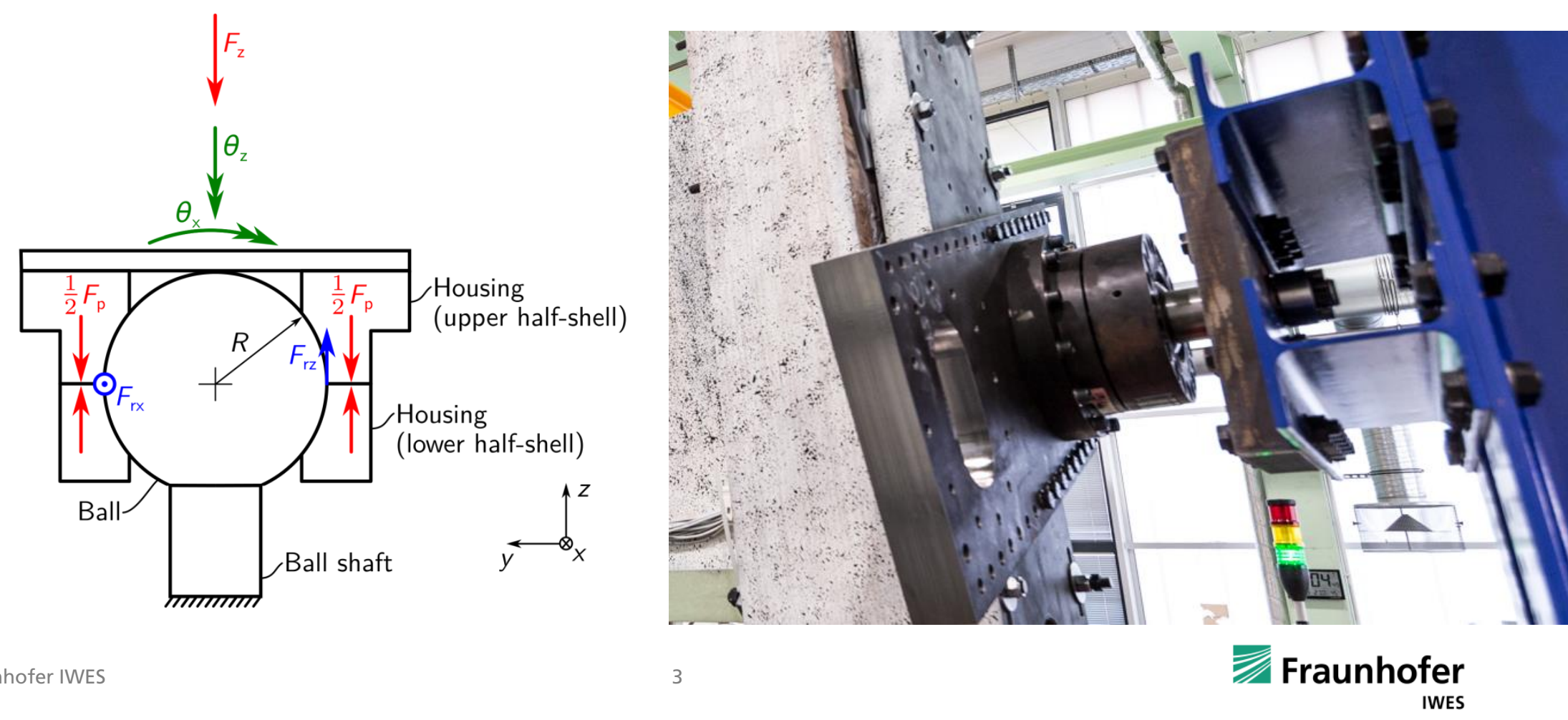


\section{Methods}

Detailed ball joint model - Finite element discretization

- Implemented in Mechanical ANSYS Parametric Design Language (MAPDL)

- Ball modelled as sphere type of TARGE170

- Housing meshed SOLID185 elements

- Contact between ball and housing with CONTA174 using penalty stiffness method

- Bolts modeled and pretensioned

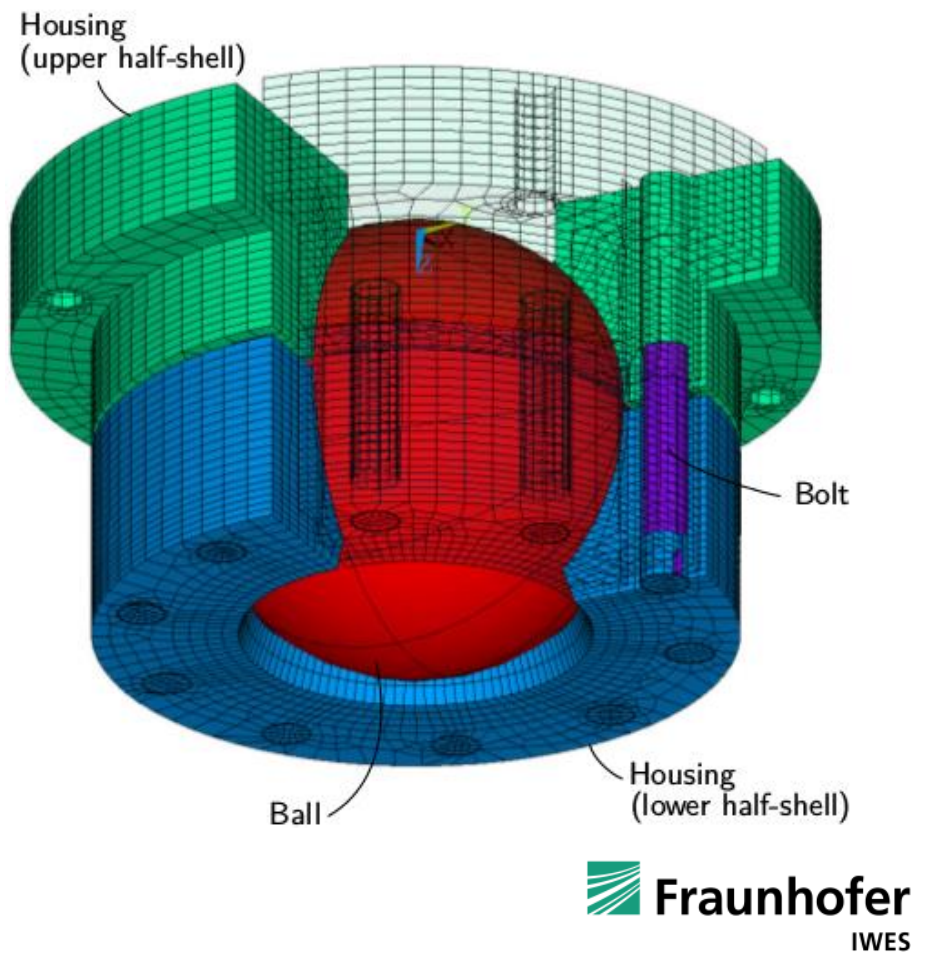




\section{Methods}

\section{Analytical ball joint model}

Friction moment for ball pressed into half-shell (Tzou 1991):

$M=F R \frac{\mu}{\sqrt{1+\mu^{2}}}$

Friction moment for pretensioned BJ:

$M=k 2 F_{\mathrm{p}} R \frac{\mu}{\sqrt{1+\mu^{2}}}$

$k=1.5$ (derived from detailed solid $\mathrm{FE}$ )

$F=2 F_{\mathrm{p}}$ (two half-shells pretension)

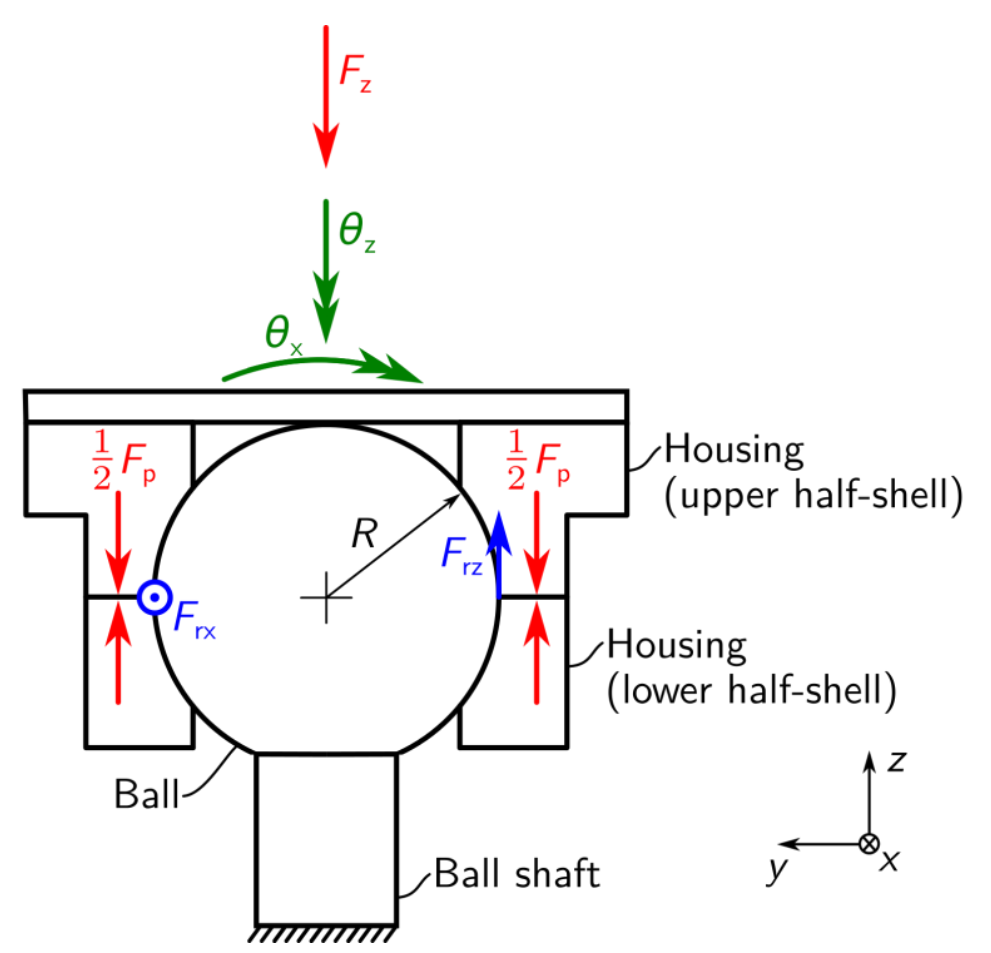




\section{Methods}

\section{Simplified ball joint model - Finite element discretization}

- Should behave like analytical model

- Implemented in Mechanical ANSYS Parametric Design Language (MAPDL)

- Housing meshed with SHELL281

- Ball modelled as sphere type of TARGE170

- Contact between ball and housing with CONTA174 using penalty stiffness method

- Tuned CNOF factor to match the analytical solution

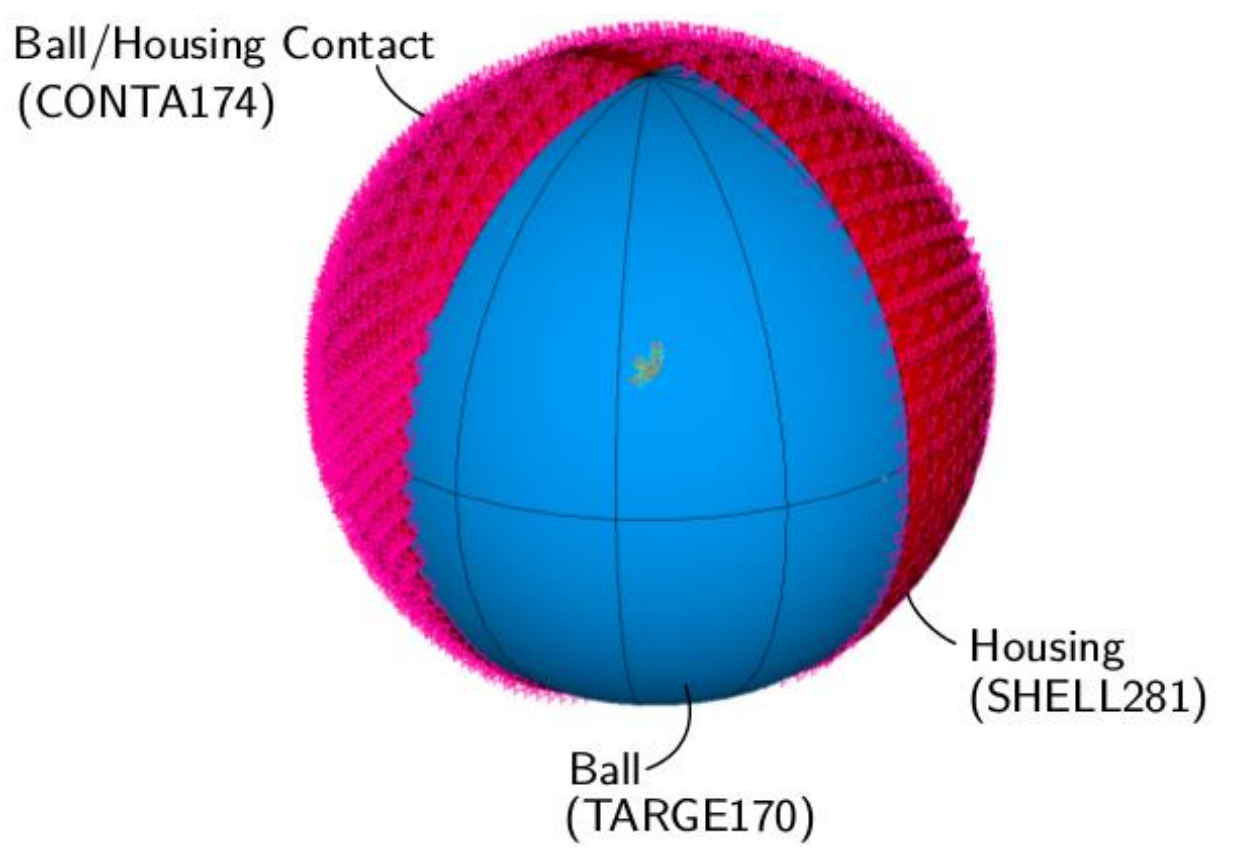




\section{Methods}

\section{Beam experiment}

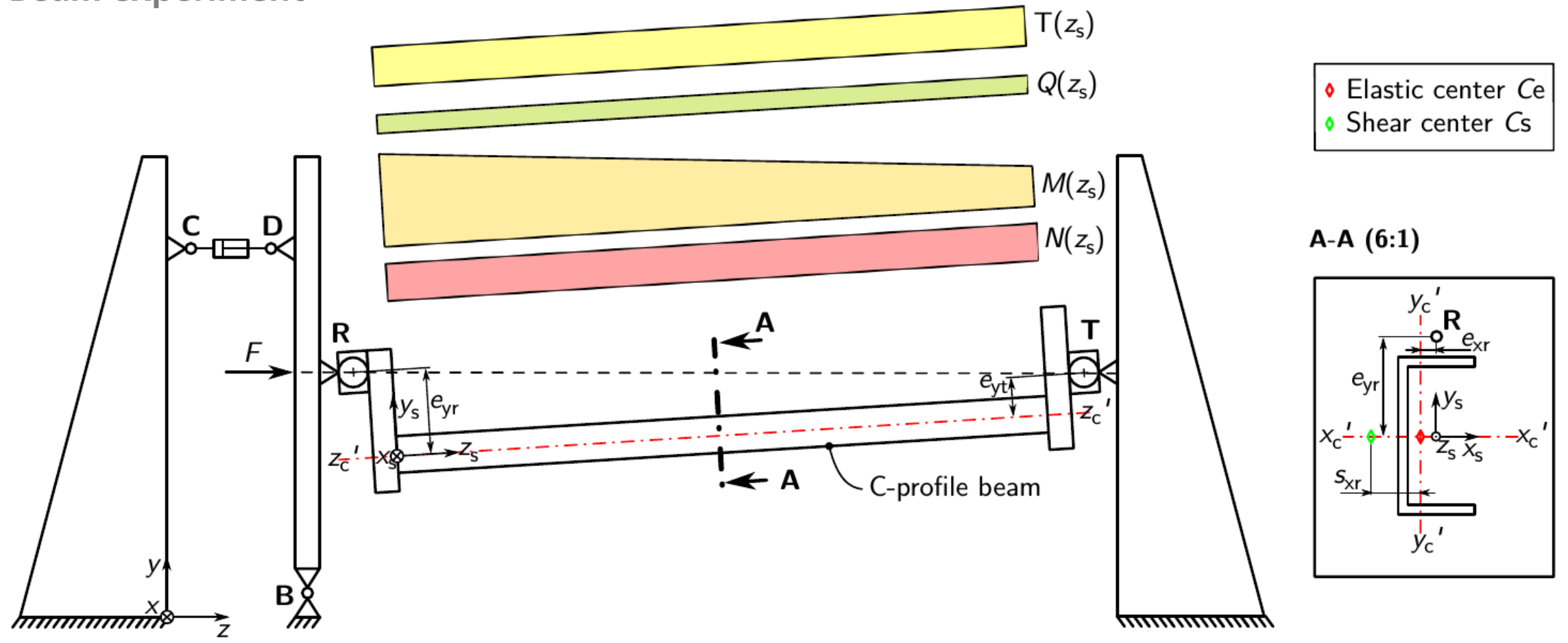




\section{Methods}

\section{Beam experiment - Measurement equipment}

- 8 markers with speckle pattern were tracked with a stereo camera system

- A digital image correlation system (DIC) determined displacements of markers

- Twist along $z$-axis calculated from top

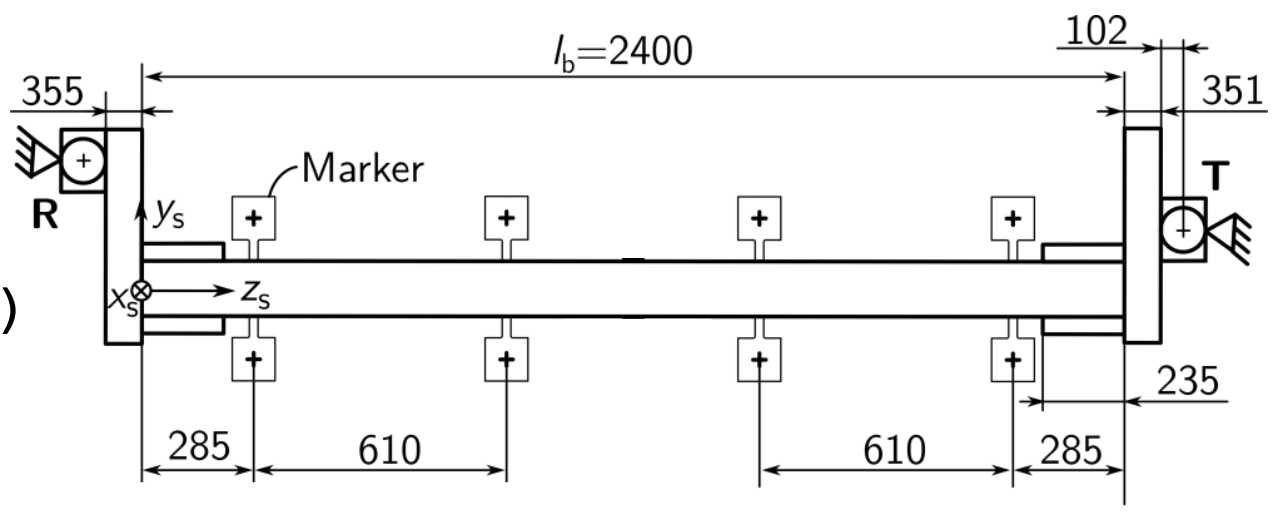
and bottom marker pairs

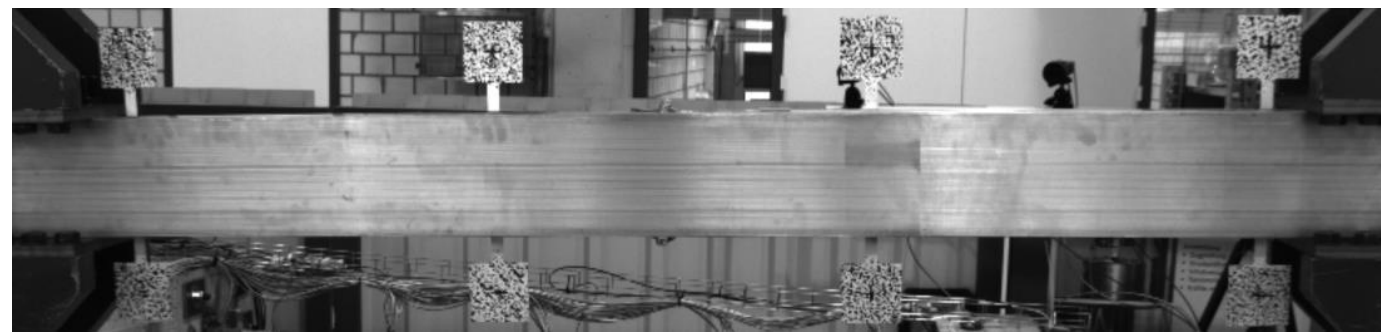




\section{Methods}

\section{Beam model - Finite element discretization}

- 2 ball joint models

- BEAM189 type used with C-shaped section

- Rigid MPC184 connected joints with beam

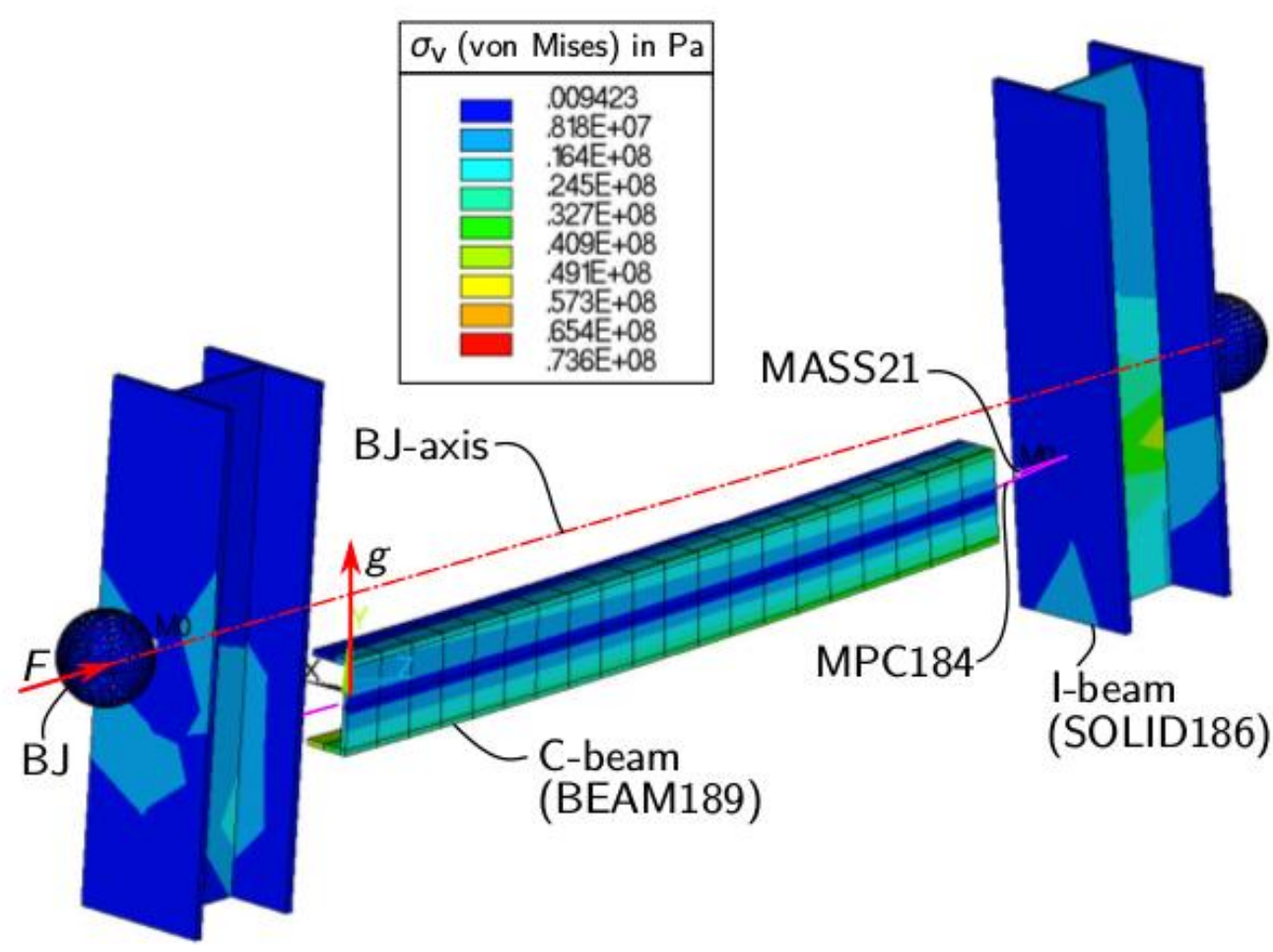




\section{Results and Discussion}

Displacements

- Friction coefficient in ball joint was varied between $\mu=1.5 \mathrm{E}-4$...5.0E-4

- Good fit
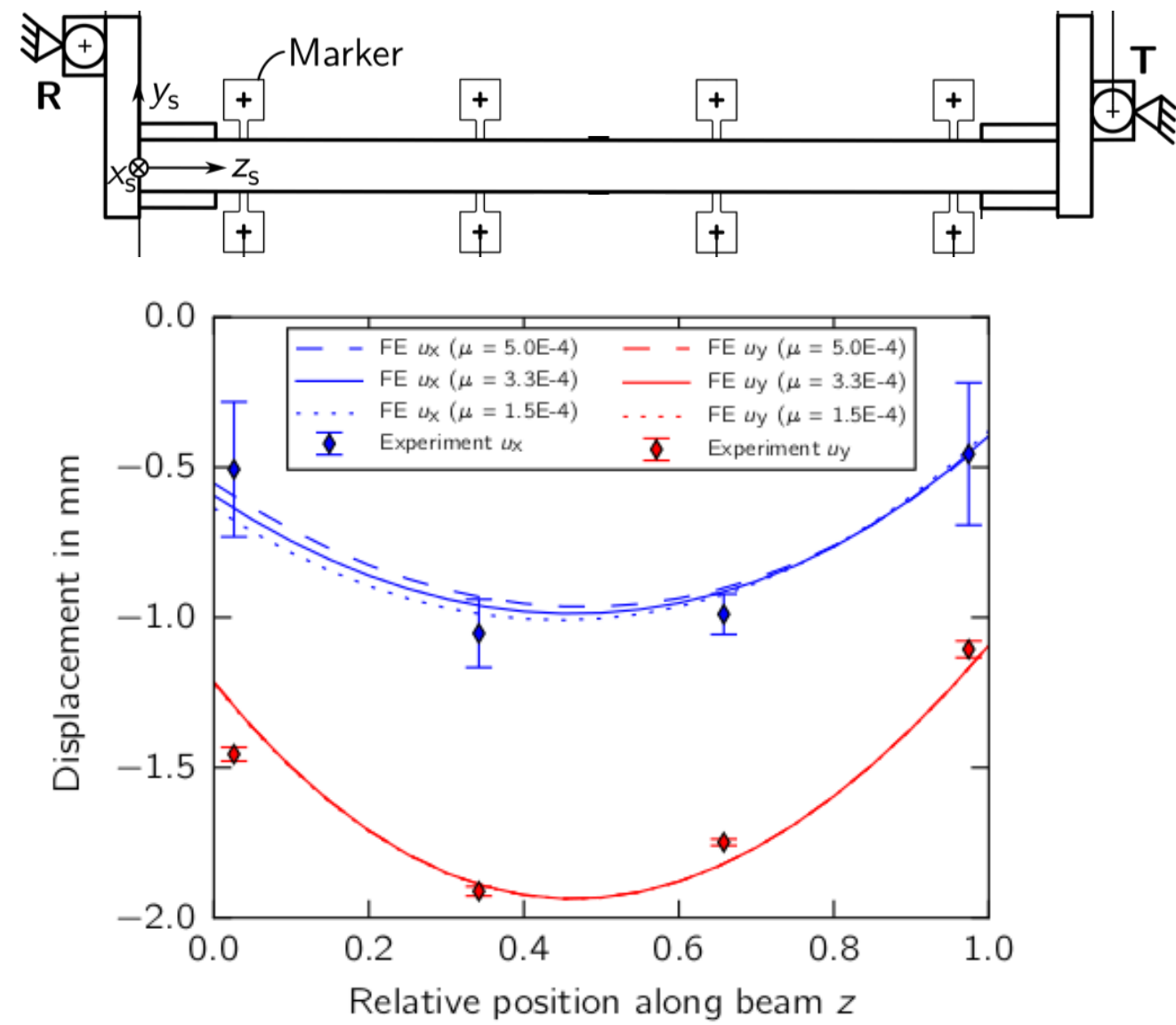


\section{Results and Discussion}

Twist along span

- Model's twist response is sensitive w.r.t. $\mu$

- Model has a good match with $\mu=$ 3.3E-4 for $\Delta \vartheta_{z}=0.055^{\circ}$ between beam ends

- Only measurement value at $z=0.35$ does not fit well
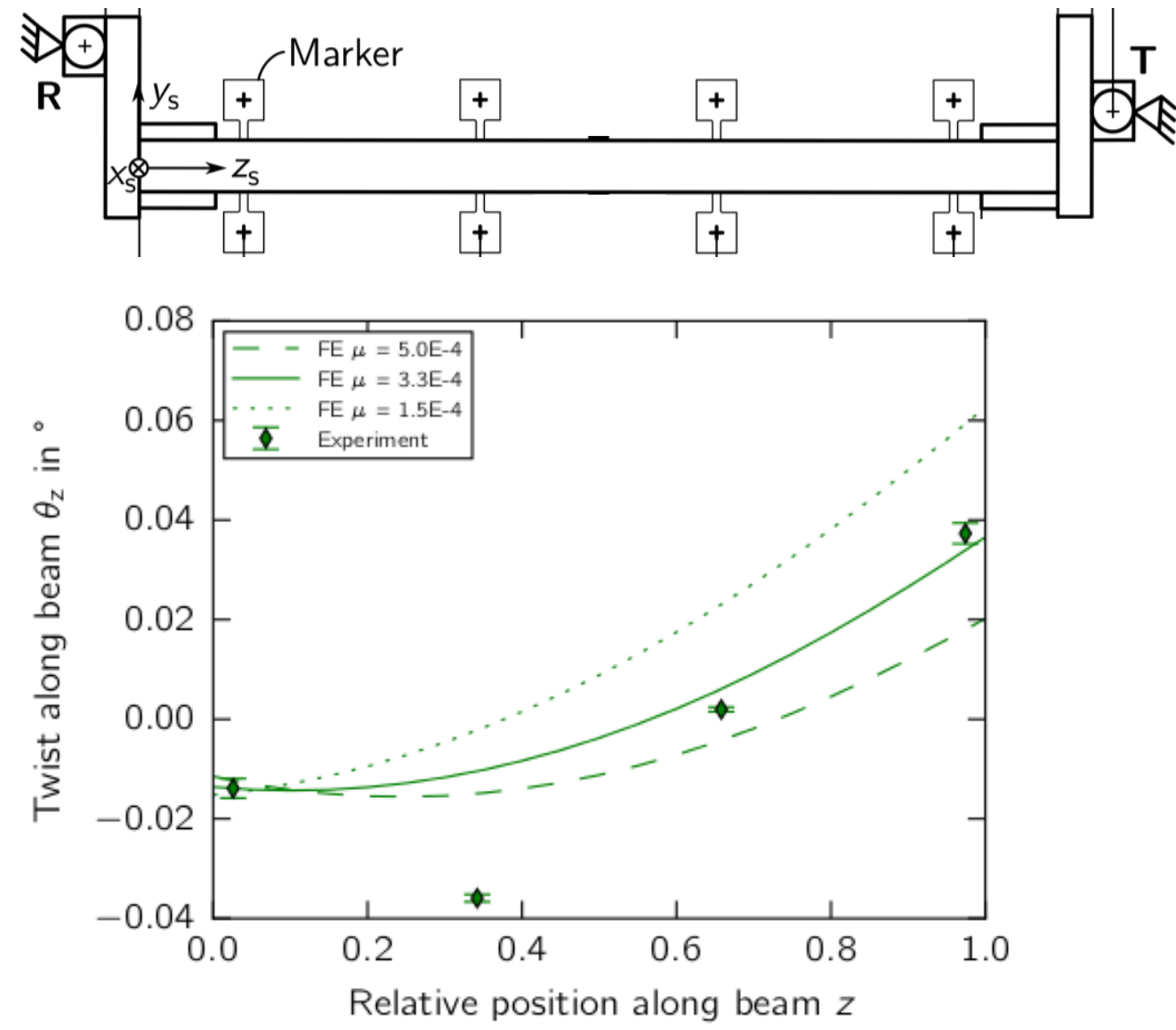


\section{Conclusions}

- Simplified BJ FE model of ball joint successfully implemented in MAPDL and verified with detailed solid FE model and analytical solution

- Simplified BJ and beam modeled experiment and revealed a friction coefficient of $\mu=3.3 \mathrm{E}-4$

- Friction coefficient of $\mu=3.3 \mathrm{E}-4$ leads to a friction moment given by $B J$ manufacturers datat sheet

- This study validated the boundary conditions of a ball joint supported specimen, i.e., a wind turbine rotor blade component

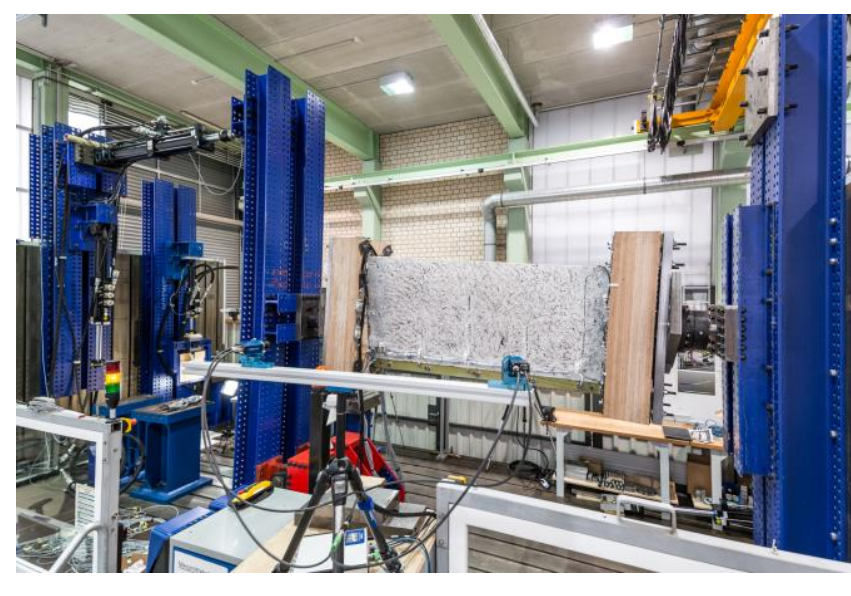




\section{Thank you for your attention!}

Questions?

Contact:

Malo.rosemeier@iwes.fraunhofer.de

David.melcher@iwes.fraunhofer.de

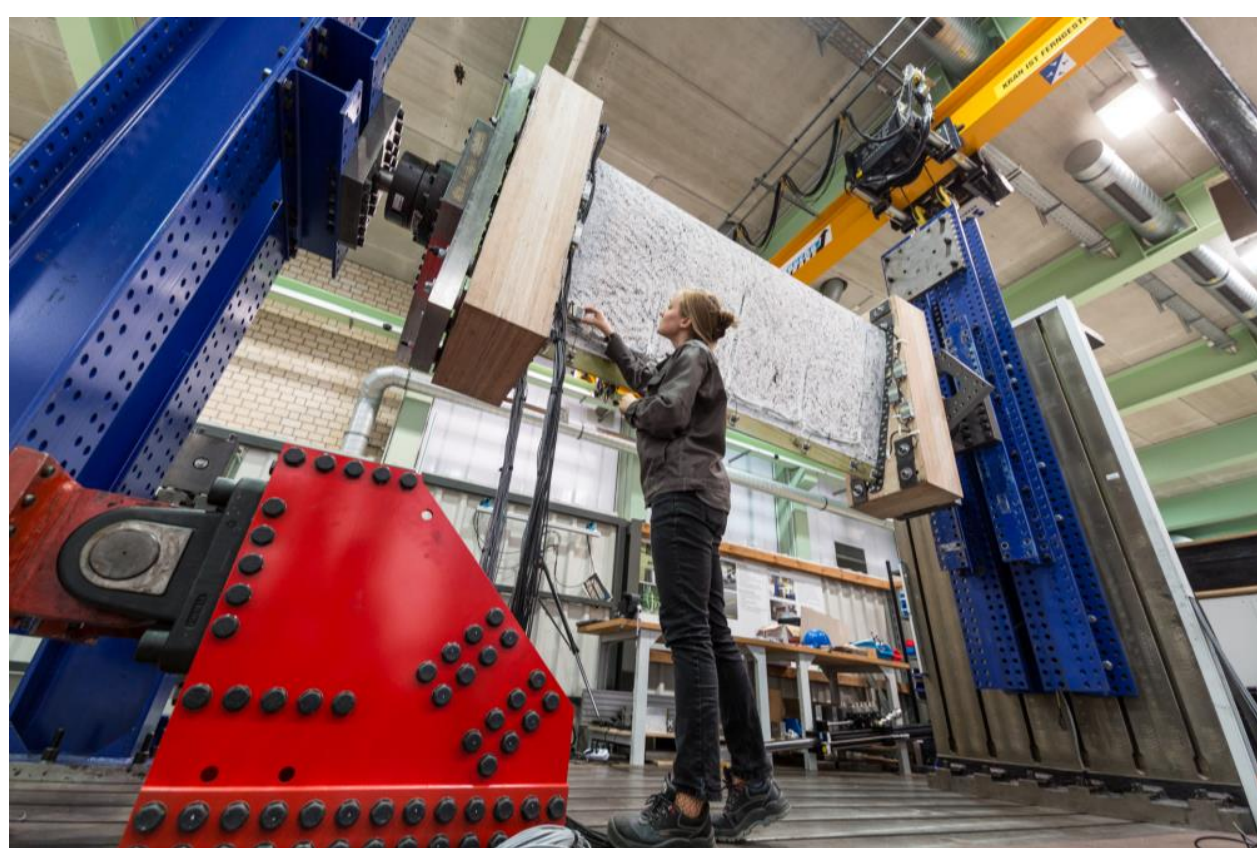

